\title{
INCLUSION MATTERS! STRATEGIES FOR IMPROVING READING AND TEST SKILLS OF SPECIAL EDUCATION STUDENTS
}

Author ORCID: https://orcid.org/0000-0002-5530-5675

Author Affiliation: Leonard B. Jackson, EdD, University of Phoenix, Phoenix, Arizona

SC Classification Genre: Education

Creative Commons Attribution (c) (1) ()

Citation: Jackson, L. B. (2021). Inclusion matters! Strategies for improving reading and test skills of special education students. Scholar Chatter, 2(1), 15-31.

http://doi.org/10.47036/SC.2.1.15-31.2021

(C) The Author. 2021. This is an open access publication through Scholar Chatter LLC.

\begin{abstract}
The purpose of this quantitative retrospective quasi-experimental study was to determine if there was a statistically significant difference between sixth, seventh, and eighth-grade classrooms filled with both general education and special education students (mild to moderate disability) receiving multiple instructional strategies and sixth, seventh, and eighth-grade classrooms filled with general education students receiving only traditional instructional strategies. Students scoring 800 or above met reading standards for the year. Results of the analysis indicated students receiving traditional instructional strategies achieved a mean score of 830 . The inclusion students receiving multiple instruction interventions also showed grade-level reading proficiency on the standardized test with a mean score of 818 . The researcher focused on the issue to show there are positive outcomes from implementing inclusion. Recommendations involving a reading intervention such as guided reading groups, backwards design planning, and collaborative instruction were noted. A one-way Analysis of Variance (ANOVA) analysis tested significance and two-way ANOVA tested interaction. Both analyses were set at the.05 significance level to interpret the data.
\end{abstract}

Keywords: Special education, General education, Disabilities, Inclusion, CRCT, Standardized Reading Tests. 


\section{Introduction}

Many aspects of inclusion comprise mainstreaming, incorporating, least restrictive environments, and regular education programs (Sauer \& Jorgensen, 2016). Educators use substitution terms; others develop differences between various forms of inclusion. Also, much of the misunderstanding over issues of inclusion derives from the usage of other related terms (Young \& Courtad, 2016). Incorporating various inclusion strategies is also necessary when teaching students with various levels of disabilities (Bruggink et al., 2016). This particular model provides the practical and rational foundation of special education services (Gilham \& Tompkins, 2016). Moreover, inclusion instructional strategies benefit students with learning deficiencies and non-learning deficiencies (Spoede et al., 2016). Reading is a necessary skill that is the foundation for comprehension (Truesdell \& del Prado Hill, 2015) and in western culture, reading is a skill needed for success in many aspects of day-to-day life (Bruggink et al., 2016).

The general problem is many educators in Georgia teaching middle school general education and inclusion students believe using the inclusion model does not help ensure students' performances on standardized testing and display resistance in implementing this model for that reason. However, inclusive practices for reading are widespread and many general and special education teachers are working together to help students, particularly in urban school settings master specific reading skills (Moje, 2017). Reading skills help prepare students for standardized reading tests (Swanson et al., 2016).

The implementation of inclusion could impact the reading scores of special education students if various multiple instructional strategies were used as opposed to using traditional instructional strategies. Traditional instructional strategies are implemented in traditional classroom settings for general education students in the sixth, seventh, and eighth grades. Therefore, the inclusion model was deeply analyzed.

\section{Research Question and Hypothesis}

RQ1: Is there a statistically significant difference in the reading test scores of the sixth, seventh, and eighth-grade students receiving MIS and the reading test scores of the sixth, seventh, and eighth-grade students receiving TIS?

Hypothesis was based on archived data on the Reading Criterion-Referenced Competency Test (CRCT) for sixth, seventh, and eighth-grade students. A one-way ANOVA and a two-way ANOVA analysis at.05 level of significance were used to measure data. The alternate hypothesis was accepted.

$\mathrm{H} 1 \mathrm{a}$ : There is a statistically significant difference in test scores between special education students receiving MIS and in test scores of students receiving TIS.

\section{Literature Review}

\section{Five Reading Components}

The five components of reading are phonics, phonemic awareness, fluency, vocabulary, and comprehension, and each component is addressed at various levels in reading instruction 
throughout a student's educational experience (Barth \& Elleman, 2017). These components are linked closely to one another in that each skill is a building block to the next. Phonics includes the relationship between written and spoken letters and sounds and is the basis for reading. Letters are identified and matched with sounds they make for words to come together in what is referred to as phonemic awareness (Fracasso et al., 2016). Phonics instruction allows students to learn word recognition more quickly because they learn keys for decoding new words (Spoede et al., 2016). Finally, comprehension, or the understanding of meaning in the text, is the next step for a beginning reader and can only occur when words are read correctly and with fluency and meanings of those words are understood (Claravall, 2016). Sixth, seventh, and eighth grades study the five components of reading extensively because students are still taught all of these components in some way (Amendum et al., 2017).

\section{The Reading Block: Sixth Grade}

In a one-hour block of a sixth-grade reading, the expectation is to see phonics overload. Whether the school employs whole language or phonics-only instruction, the classroom would be rich with literacy (Goodwin, 2015). All reading materials in the classroom should be at an intermediate level and should reinforce phonics skills students are learning (Peake et al., 2016). An administrator, for example, would see mini-lesson charts with words, context clues, and sequences of events all over the classroom as students continue learning not only names of dayto-day items, but words and terms associated to those items (Ainsworth et al., 2016). The administrator would most likely observe a reading educator teaching an extended lesson on comprehension during this block because teacher modeling of reading fluently is the key at this stage (Fracasso et al., 2016).

\section{The Reading Block: Seventh Grade}

Most students in the seventh grade become proficient at predicting outcomes, sequences of events, and main idea concepts, without much effort. Students in the seventh grade are now focusing more on understanding the message being carried by the text (Özbek \& Girli, 2017). Seventh graders know they are reading for some purpose-to learn, to comprehend, and to answer story comprehension questions. Although still working on phrasing and decoding longer words, students are more fluent with another year of reading instruction behind them (O'Connor et al., 2017). The seventh-grade classroom will still be "rich with literacy," but will move beyond walls covered with blends, digraphs, the sequence of events, and predicting outcomes (Boucher et al., 2016). Literature appropriate at seventh-grade reading levels will be discernible, but books will probably consist of more varied genres (Claravall, 2016).

\section{The Reading Block: Eighth Grade}

Eighth graders are applying these skills to their entire subject areas with strong reading foundations built in grades one through seven (Barth \& Elleman, 2016). Eighth graders must learn to process texts that are more challenging, as they will encounter grammar, unfamiliar words, and complex ideas (Berninger et al., 2016). They need to learn how to learn from reading, as well as how to be critical of what they read. After the eighth grade is high school, and at this stage is where most students become lifelong readers (Louick et al., 2016). In an eighth-grade 
classroom, an administrator would observe little or no phonics instruction. The focus of reading shifts almost exclusively to comprehension. Phonics skills are woven into spelling and vocabulary lists and more in-depth word recognition strategies are employed (Mattison, 2015). Word roots, affixes, and their meanings are taught more than individual phonemic sounds, and vocabulary is often taught using this method (Crosson \& McKeown, 2016). The administrator would observe much less oral reading from the teacher and more paired and independent reading from students (Snow \& Matthews, 2016).

\section{Inclusion/Special Education Students}

Inclusion in education is an instructional strategy model for educating students, who are identified with special educational needs (Gilham \& Tompkins, 2016). The inclusion model is designed for students with special needs to receive instruction in their academic setting with nondisabled students. The inclusion model and implementation of these models and practices often varies. Inclusion students are tested on state standards annually (Schimmel \& Ness, 2017).

\section{Theoretical Framework}

Special education and behavioral analysis theories, which help educators better understand student patterns in learning behaviors, are traced back to Watson's determinism theory and Vygotsky's sociocultural learning theory. Determinism is defined as an attitude supporting beliefs that the universe is a lawful and orderly place in which all occurrences happen as the result of other events (Hudson et al., 2015). Vygotsky's sociocultural theory was also researched to help shape the framework of this particular study. The sociocultural theory of human learning is based on the premise that learning can involve a social aspect. Also, it is the origin of human intelligence (Kushwaha, \& Rao, 2016). The significant aspect of this theoretical framework is social interactions are the main development of cognition (Edwards, 2017).

Learners have a way of learning information on two levels. The first level of learning is via interaction with others. The second way is learning through the integration of the individual's mental capacity (Orellana et al., 2017). In other words, every function in a learner's cultural development appears at least twice. Learning takes place on a social level and an individual level (Orellana et al., 2017).

There is a second aspect of Vygotsky's theory; the idea the potentiality for cognitive development, for instance, is limited to a zone; the zone of proximal development [ZPD] (Clarà, 2017). This particular zone is where the exploration for which learners are cognitively prepared (Maftoon et al., 2017). Educators or individuals that are more experienced can assist learners with scaffolding to support the students' understanding of complex skills development or knowledge domains (Bakker \& Smit, 2017). Educators can offer learners a collaborative learning experience via modeling effective strategies that support their intellect, knowledge, and skills that fosters and facilitates learning that is intentional (Golombek, 2017).

\section{Methodology}

Quantitative methodology was more appropriate for this study. Quantitative was selected because I wanted to see if there was a statistical significance between reading test scores via 
implementing two instructional methods: multiple instruction and traditional instruction. The data were used to help the researcher determine relationships between variables of interest. The data sets were used to measure achievement levels. Six sets of scores from archival data were analyzed in the study-two sets in the sixth grade, two in the seventh grade, and two in the eighth grade. The Georgia CRCT served as the testing instrument.

\section{Population/Participants}

A total of 180 students' reading test scores was sampled. The sampled scores derived from six reading groups. Group A: 30 sixth-grade students, 30 seventh-grade students, and 30 eighth-grade students were in the treatment group using multiple instructions (inclusion). Group B: 30 sixth-grade students, 30 seventh-grade students, and 30 eighth-grade students were in the non-treatment group using traditional instruction.

\section{Instrumentation}

Instruments used in this particular study were validated score sheets and results from the CRCT, which was the standardized test taken in grades three through eight in Georgia. Quantitative instruments are in the form of some type of standardized assessment (Bacca et al., 2016).

\section{Validity and Reliability}

The Criterion-Reference Competency test meets standards set by the federal government (Georgia Department of Education, 2016). The reliability of the instrument allowed the opportunity to analyze data produced from the instrument. Validity is a form of a test that accurately measures objectives it is supposed to measure; specifically, assessments should have content validity (Haynes et al., 2017).

\section{Internal Validity}

The federal government validated the CRCT document internally as a document that could accurately determine student success (Georgia Department of Education, 2014). The primary threat to internal validity was the inability to select participants randomly since they were already assigned to classrooms.

\section{External Validity}

Researchers also need to concern themselves with external validity (Georgia Department of Education, 2016). This research concept pertains to the extent to which a study or research conclusions are generalized from respondents, or a research sample to a larger population.

\section{Reliability}

Reliability of the study is seeing if the study is replicable using the same procedures (Polanin et al., 2016). The reliability of the instrument will provide an opportunity to analyze data produced from the instrument. The researcher will examine test data to determine the reliability of test scores by estimating the amount of error in the score (McMillan, 2016). 


\section{Data Collection}

Data from CRCT scores were collected and analyzed. Participation in the study did not require the use of students beyond the middle school level. The CRCT was given each year. The reading portion of the CRCT was analyzed. Students were considered meeting standards for reading at the middle school level when they scored an 800 and above. Students scoring an 850 and above were considered exceeding the standard for reading at the middle school level.

\section{Data Analysis}

The data analysis approach for this study included using the quantitative statistical application, Statistical Package for Social Sciences (SPSS) for analyzing data from test scores to help define increases and discrepancies between inclusion students and general education students. Data analyses included an inferential one-way ANOVA and two-way ANOVA analysis for determining if there was a significant difference between inclusion-reading test scores among multiple (inclusion) and traditional groups.

\section{Findings}

The means and standard deviations of the sixth grade, seventh grade, and eighth-grade CRCT scores in reading were also analyzed. Initially, archival reading scores were obtained for 180 students. It is important to mention the outlier briefly. In order to assess the univariate normality for the reading score, a box plot was created. The box plot found one student with an unusually high reading score (outlier). The student was removed from the sample leaving the final sample of $N=179$. The mean score of the traditional group was 830 , while the mean score of the inclusion group was 818 . There was a statistically significant difference in scores on the CRCT in reading between students who were in classes using MIS. A one-way ANOVA of independence was conducted.

Table 1 displays the frequency counts for selected variables. There were more students in the multiple group $(61.5 \%)$ than in the traditional group $(38.5 \%)$. The breakdown based on gender found somewhat more boys in the sample (53.1\%) than girls (46.9\%). When an interaction variable was created combining group and gender, the largest of the four groups were multiple boys (32.4\%) and the smallest group was traditional girls (17.9\%) (see Table 1).

Table 1. Frequency Counts for Selected Variables $(N=179)$

\begin{tabular}{llrr}
\hline \multicolumn{1}{c}{ Variable } & \multicolumn{1}{c}{ Category } & $n$ & $\%$ \\
\hline Group & Multiple & 110 & 61.5 \\
Gender & Traditional & 69 & 38.5 \\
& Boys & 95 & 53.1 \\
Group X Gender & Girls & 84 & 46.9 \\
& Multiple Boys & 58 & 32.4 \\
& Multiple Girls & 52 & 29.1 \\
& Traditional Boys & 37 & 20.7 \\
& Traditional Girls & 32 & 17.9 \\
\hline
\end{tabular}


The question was answered by displaying Table 2 . This particular table displays the oneway ANOVA test comparing the two types of instructional strategies. Traditional group students $(M=830.07)$ had significantly higher reading scores than did the multiple group students $(M=$ $818.17)(F[1,177]=15.43, p=.001)$ (see Table 2$)$. This finding provided support to reject the null hypothesis in favor of the alternative hypothesis, which stated there is a statistically significant difference in reading test scores of the sixth, seventh, and eighth-grade students receiving MIS and reading test scores of the sixth, seventh and eighth-grade students receiving TIS.

Table 2. One-Way ANOVA Tests for Reading Score with Selected Independent Variables $(N=$ 179)

\begin{tabular}{llrccccc}
\hline $\begin{array}{c}\text { Independent } \\
\text { Variable }\end{array}$ & \multicolumn{1}{c}{ Category } & $n$ & $M$ & $S D$ & $\eta$ & $F$ & $p$ \\
\hline Group $^{\text {a }}$ & Multiple & 110 & 818.17 & 19.92 & & & \\
& Traditional & 69 & 830.07 & 19.42 & & & \\
Gender $^{\text {a }}$ & Boys & & & & .13 & 3.19 & .001 \\
& Girls & 95 & 820.20 & 17.94 & & & \\
Group X Gender $^{\mathrm{b}}$ & & 84 & .825 .65 & 2284 & & & \\
& Multiple Boys & 58 & 816.47 & 18.21 & & & \\
& Multiple Girls & 52 & 820.08 & 21.68 & & & \\
& Traditional Boys & 37 & 826.05 & 16.06 & & & \\
& Traditional Girls & 32 & 834.72 & 22.05 & & & \\
\hline
\end{tabular}

${ }^{a}$ No post hoc tests needed due to only two categories for this variable.

${ }^{\mathrm{b}}$ Scheffe post hoc tests: $4>1(p=.001) ; 4>2(p=.01)$; no other test was significant at the $p<.05$ level.

\section{Additional Findings}

Table 2 displays the one-way ANOVA test comparing reading scores based on gender. Girls $(M=825.65)$ tended to have higher reading scores than did the boys $(M=820.20)(F$ $[1,177]=3.19, p=.08$ ) (Table 2 ). In addition, Table 2 displays the one-way ANOVA test comparing the independent variable created from the interaction of group and gender. The overall test was significant $(F[3,175]=6.64, p=.001)$. Scheffe post hoc tests found traditional girls $(M=834.72)$ to have significantly higher reading scores than either the multiple boys $(M=$ 816.47) ( $\mathrm{p}=.001)$ or the multiple girls $(\mathrm{M}=820.08)(\mathrm{p}=.01)$ (Table 2). 


\section{Two-Way ANOVA Analysis}

\section{Data Based on Gender}

A two-way ( $2 \times 2$ factorial) ANOVA was conducted to determine if differences existed in the scale scores of the sixth, seventh, and eighth-grade CRCT in reading based on gender and type of instruction (groups). Table 3 displays the two-way ANOVA test for reading score based on group and gender. The full model was significant $(F[3,175]=6.64, p=.001)$ and accounted for $10.2 \%$ of the variance in the students' reading scores. The main effect for group found traditional group students $(M=830.39, S E=2.37)$ to have significantly higher reading scores than the multiple group students $(M=818.27, S E=1.87)(F[1,175]=16.13, p=.001)$. The main effect for gender was also significant with girls having significantly higher reading scores $(M=$ $827.40, S E=2.20)$ than the boys had $(M=821.26, S E=2.06)(F[1,175]=4.14, p=.04)$. However, no significant group X gender interaction effect was found $(F[1,175]=0.70, p=.40)$.

Table 3. Two-Way ANOVA Test for Reading Score Based on Group and Gender $(N=179)$

\begin{tabular}{lrrrrrr}
\hline \multicolumn{1}{c}{ Source } & \multicolumn{1}{c}{$S S$} & \multicolumn{1}{c}{$d f$} & \multicolumn{1}{c}{$M S$} & \multicolumn{1}{c}{$F$} & \multicolumn{1}{c}{$p$} & Partial Eta Sq \\
\hline Full Mode $_{\text {Group }^{\mathrm{a}}}$ & $7,650.19$ & 3 & $2,550.06$ & 6.64 & .001 & .102 \\
Gender $^{\mathrm{b}}$ & $6,196.47$ & 1 & $6,196.47$ & 16.13 & .001 & .084 \\
Group X Gender $_{\text {Error }}^{1,590.54}$ & 269.51 & 1 & $1,590.54$ & 4.14 & .04 & .023 \\
Total & $67,242.48$ & 175 & 269.51 & 0.70 & .40 & .004 \\
\hline
\end{tabular}

${ }^{a}$ Group: Multiple $(M=818.27, S E=1.87)$ versus Traditional $(M=830.39, S E=2.37)$.

${ }^{\mathrm{b}}$ Gender: Boy $(M=821.26, S E=2.06)$ versus Girl $(M=827.40, S E=2.20)$.

As indicated via findings, it is concluded that special education students, who are placed into a multiple instruction (inclusion) setting, can be successful on the state standardized test. Findings also showed success on-the CRCT is dependent upon individual students who score 800 or above on the CRCT in reading. Students who score at least 800 or above are considered to meet or exceeded the standards required to pass the test. However, students who failed or scored at least 815 on the state level test required additional support beyond a Tier 1 related intervention to ensure they passed the test the following year. As it related to the findings, individual students were divided into at least three groups based on their scores on the grade level CRCT in reading. Findings were able to show via table individuals scoring between 800 and 815 as well as individuals scoring at or above 825 can be proficient on the CRCT.

\section{Discussion}

Schools have a responsibility for ensuring students can achieve mastery on statemandated tests (Haynes et al., 2017). There is substantial research validating the effectiveness of inclusion in increasing the academic achievement of students with disabilities, many administrators implemented inclusion in their schools to fulfill these requirements and promoted the learning of all students (Hamdan et al., 2016). Accountability is placed on the school to 
ensure all students are successful at achieving state standards (Snow \& Matthews, 2016; Swanson et al., 2016; Vinovskis, 2015). The study's findings were specific to inner-city area schools with low-socioeconomic characteristics as outlined by federal Title I funding. Students must acquire skills to master state tests put in place by NCLB (Bell, \& Bogan, 2015).

Findings of this study were specific to schools within the urban area with lowsocioeconomic characteristics. Table 3 presented the results of the ANOVA. The conclusion was there was a level of significance among the instructional type, but not a significant interaction between male and female interaction concerning reading scores. However, the findings revealed female students were better prepared for standardized testing in both instructional settings than males. There was a significant main effect on the type of instruction indicating overall.

The findings revealed that using inclusion as an instructional strategy can work once correctly implemented. Also based on these findings, evidence suggested special education students, who were placed into general education classrooms during the 2013-2015 school years to improve reading skills, were successful at passing the Georgia CRCT at the end of the year. Students must acquire skills to master state tests put in place by NCLB (Bell \& Bogan, 2015). The research from Chapter 2 supports the use of interventions to help students who are not meeting state standards (Howell et al., 2016).

\section{Limitations}

The study was limited to middle schools whose parents agreed to allow their students to participate in the study. Consent letters were sent home with the students and if their parents chose not to allow the student to participate, the students' scores were not included in the analysis. This limitation was also reflected in the number of students enrolled in the middle schools. This limitation might relate to the lack of participants, which could limit researchers from conducting a study focusing on inclusion. This includes the number of students enrolled in each class. The lack of access to certain areas within the given facility or facilities may also present a limitation. This limitation might include restricted information concerning students.

Small sample sizes, which may include reducing the number of students taking the test, may also present a limitation. Furthermore, this research was also limited by school districts. Another limitation involved how many traditional and inclusion students were receiving only the collaborative instruction as needed. Collaborative instruction is allowing students to work together on assignments. Collaborative instruction was implemented for students to perform specific learning goals.

\section{Recommendations for Practice in the Reading/Inclusion Classroom}

Based on the results of the study, many recommendations follow regarding future reading inclusion practices for educators. Since some general educators do not have the proper training to implement inclusion practices, one recommendation is to have educators take professional development classes to address these ongoing issues, such as lack of proper support to help them meet the needs of special education students. An additional recommendation is making sure both remedial and general educators take proper measures to address retention rates and other 
important factors that could help close the achievement gap. The basis for this recommendation is on specific goals set to help all educators in special education work toward closing the achievement gap.

A further recommendation is the implementation of some type of reading and practical intervention strategies based on data analysis results. The basis for this recommendation is on baseline scores between 800 and 815 . Although inclusion students passed the CRCT reading portion, interventions need to be in place for students barely meeting standards for the CRCT. Also, educators should consider a continuation of tier intervention support for students scoring below 815 on the CRCT based on previous year's scores.

It is also recommended both general and special education teachers exert more effort to adapt their instructional practices to help students achieve as mandated by local state educational laws. Remediation and intervention strategies should place a rigorous focus on helping all students, especially students with learning disabilities; improve reading skills such as fluency, decoding, and vocabulary acquisition to improve their ability to read across the curriculum. A final recommendation is to make sure every teacher working with inclusion students keep up with the latest reading practices to ensure they are prepared to handle different types of learning disabilities that come with assisting special education students. There are many classifications for disability students: mild learning disabilities, serve learning disabilities, and so many more. Teachers who take specific certified professional reading courses for certification units would support their professional interests in achieving more effective pedagogies (Spoede et al., 2016).

\section{Recommendations for Special and General Education Teachers}

Inclusive classrooms have many students with various needs. Students' needs range from EBD to severe learning disorder exceptionalities mainstreamed into the general education classroom. On the other hand, at least three to four students per day may spend part of their day in both general and special education classrooms. The role of both general and special education teachers is to help create a learning community that is inclusive in ensuring students are meeting their behavioral and academic goals. However, special education and general education educators should depend on each other to accomplish these goals. Ongoing communication is critical in providing the best supplemental material, location, and services to best support all students. These recommendations apply to special and general education teachers including those in Georgia. Inclusion students could have opportunities to achieve a satisfactory score on the reading assessment if inclusion instructional methods are correctly implemented.

\section{Begin at the End}

The backward design planning is one of the best ways to align daily units, tests, classroom discussions and all reading units with year-end reading achievement goals (Golombek, 2017).. This involves implementing a multi-step process. General and special educators can sit down and consult all records of the special education students, particularly their IEPs to help determine what is considered overachieving academic and behavioral goals. Teachers could figure out how these particular goals align with state and national standards as well as how these goals met year-end goals for all students in the classroom. Curriculum map review can help to 
figure out which reading units, for instance, will assist in meeting year-end goals. Based on the information, both teachers could design individual reading lessons within the units that align with the goals of helping special education students meet state testing goals.

\section{Embrace Universal Design}

This approach to developing a lesson makes each lesson accessible to all learners regardless of students learning styles, backgrounds, and ability levels; and, many strategies may lead to achieving the goal. General and special educators can both use visual or written material to communicate reading objectives. Both can also rely on communicating lessons verbally to ensure all learners have a grasp of the reading concepts outlined. Verbally, both teachers could ask students to share what they learn via presentations, drawings, and writings. Computerized reading lessons may also be helpful to engage students. All of these approaches are to ensure learners are included in the lessons. This procedure could also be helpful in reaching students with special needs while allowing them to sharpen their thinking and decoding skills. Students would be able to retain the new information, moving it from short-term to long-term memory.

\section{Formulate a Flexible Behavior Management Plan}

Effective planning is critical for both special and general educators. Effective teaching and planning in an inclusive classroom will depend on how well each teacher has control of the classroom. Effective classroom management requires being assertive and communicative of all goals and expectations. Both the general and special education educators will need to tailor classroom environments to suit all learners, especially special needs students. These students have a diverse set of needs that take time and patience. Teachers could create lists or action plans for students, including students with learning needs. The list could include words to review individual work with the learners. The student list or action plan includes, but is not limited to how to put items away at the end of class, and how to do independent work, such as reading and writing assignments.

\section{Collaborative Instruction}

Collaborative instruction could help reading students beyond the implementation of inclusion instruction. Collaborative instruction could help educators have a direct connection to students with learning disabilities (Boardman et al., 2016). Some teachers do not teach in an inclusion environment and need support, practice, and assistance to develop habits supportive of all students. In an inclusion environment, if a student asks for help, any educator, who could better assist the student more effectively, may act.

\section{Recommendations for Leadership}

School leadership plays a critical role in assisting general and special education educators. Leaders within a school district include, but are not limited to school-based administrators, superintendents, and curriculum directors in leadership positions. Most importantly, an in-depth analysis on how inclusion can benefit special education students is essential for school leaders to research current instructional practices and identify strategies designed to help students, whose test scores fall between or below the minimal level. 


\section{Future Research Opportunities}

Researchers could analyze findings from the present study from a qualitative method with an explanatory case study design and perspective. Qualitative researchers could make use of the results of analysis from the present study and investigate inclusion classroom methods based on teacher perception. Teacher perceptions will always be an intricate part of the discussion on inclusion. Qualitative researchers could conduct interviews with educators to get their direct feedback on teaching students with learning disabilities. These qualitative researchers could analyze the feedback, look at trends to see what worked, what did not work, and what needs could be improved upon using inclusion as an instructional model.

The present study findings could also be useful for other quantitative researchers that are willing to take on a causal-comparative method. Causal-comparative methods are used to determine causes that already exist. Quantitative researchers can use this particular study as a point of reference to see if there are other unknown relationships associated with the inclusion model as a unique instructional strategy to assist learners with learning disabilities. This approach is taken if the quantitative researcher wants to explore the causes, effects, or consequences, which differ in the structure and purpose of the study.

Furthermore, certified education experts provide valuable information and resources via professional conferences. The recommendation is to have professional development meetings relative to reading instruction and inclusion strategies. These two methods of delivery would help get the information to a broader audience for implementing an active and supportive environment within the inclusion setting for special education students.

Further research analysis can also determine how the purposeful sample of students performs on future CRCT reading assessments. This task is accomplished through a tracking method such as running records. Tracking through running records monitors students' achievement levels as they advance from one grade level to the next in the middle school setting. Findings of this present study are presented to leadership teams.

School leadership team meetings would be an ideal time to discuss findings found within this present study. The study may reveal information about inclusion that general educators may not have known before the conference. Also, the findings of this research study are also implemented to help leadership provide a more positive perception of inclusion. Inclusion, as an instructional method, is implemented where leaders are working with individuals with learning disabilities.

\section{Conclusions}

Results and significance of each hypothesis concerning the purpose of the study were impacted based on findings. The connection of results is related back to the null hypothesis when the $p$-value [Sig] is less than the.05 alpha, the person in control of the research could reject the null in favor of alternative hypotheses. The investigator's data showed there was a statistically significant difference between MIS in an inclusion setting and reading scores. Also, it was 
revealed how current literature demonstrating this type of existing relationship could alarm educators that have inclusion students.

The findings indicated slight positive changes in the scores of the six groups at the end of the year for students in classrooms where MIS were implemented. In addition, these students were able to perform successfully on the standardized reading test with the use of interventionbased instruction. However, they did not score higher than the controlled group where whole group strategies were implemented using the traditional instructional model.

The statistically significant difference in the mean scores among students receiving MIS and students receiving traditional instruction strategies showed a $p$-value level of significance lower than 0.05 . The overall mean for students in the experimental group receiving inclusion instruction was 818 . The overall mean for students in the controlled group receiving a traditional instruction was 830 .

Additionally, findings could help foster or create a learning community for students with mild learning disabilities. Students with learning disabilities may frequently feel out of place. The impact of leadership implementing such instructional strategies could lead students with mild learning disabilities to continue to have a level of confidence to meet reading standards. If instructional strategies were implemented effectively, students with learning disabilities would have better opportunities and chances at succeeding on the annual Reading CRCT assessment each year.

\section{Funding}

The author received no financial support for the research, authorship, and/or publication of this article.

\section{Acknowledgements}

I would like to thank my reviewers, Dr. Elizabeth Johnston and Dr. Julie Conzelmann. Thank you for taking the time to review this article. The attention to details was critical and a significant help as it did not go unnoticed.

\section{References}

Ainsworth, M. K., Evmenova, A. S., Behrmann, M., \& Jerome, M. (2016). Teaching phonics to groups of middle school students with autism, intellectual disabilities and complex communication needs. Research in Developmental Disabilities, 56(6), 165-176. https://doi.org/10.1016/j.ridd.2016.06.001

Amendum, S. J., Conradi, K., \& Hiebert, E. (2017). Does text complexity matter in the elementary grades? A research synthesis of text difficulty and elementary students' reading fluency and comprehension. Educational Psychology Review, 30, 1-31. https://doi.org/10.1007/s10648-017-9398-2 
Bacca, J., Baldiris, S., Fabregat, R., \& Graf, S. (2016). Augmented reality trends in education: A systematic review of research and applications. Journal of Educational Technology \& Society, 17(4), 133. https://doi.org/10.1016/j.procs.2015.12.203

Bakker, A., \& Smit, J. (2017). Theory development in design-based research: An example about scaffolding mathematical language. In Making change happen (pp. 111-126). Springer Fachmedien Wiesbaden. https://doi.org/10.1007/978-3-658-14979-6_11

Barth, A. E., \& Elleman, A. (2017). Evaluating the impact of a multistrategy inference intervention for middle-grade struggling readers. Language, Speech, and Hearing Services in Schools, 48(1), 31-41. https://doi.org/10.1044/2016_1shss-16-0041

Bell, D. D., \& Bogan, B. (2015). Fluency in early childhood: Contributions from the research to support emerging and struggling readers. International Journal for Innovation Education and Research, 3(12), 111-121. https://doi.org/10.31686/ijier.vol3.iss12.492

Berninger, V., Abbott, R., Cook, C. R., \& Nagy, W. (2016). Relationships of attention and executive functions to oral language, reading, and writing skills and systems in middle childhood and early adolescence. Journal of Learning Disabilities, 50(4), 434-449. https://doi.org/10.1177/0022219415617167

Boardman, A. G., Vaughn, S., Buckley, P., Reutebuch, C., Roberts, G., \& Klingner, J. (2016). Collaborative strategic reading for students with learning disabilities in upper elementary classrooms. Exceptional Children, 82(4), 409-427. https://doi.org/10.1177/0014402915625067

Boucher, A., Evans, M., \& Graham, S. (2017). Udio: Rich and authentic literacy experiences for struggling middle school readers. In S. Crossley \& D. McNamara (Eds.), Adaptive Educational Technologies for Literacy (pp. 294-301). Taylor \& Francis. https://doi.org/10.4324/9781315647500-23

Bruggink, M., Goei, S. L., \& Koot, H. M. (2016). Teachers' capacities to meet students' additional support needs in mainstream primary education. Teachers and Teaching, 22(4), 448-460. https://doi.org/10.1080/13540602.2015.1082727

Clarà, M. (2017). How instruction influences conceptual development: Vygotsky's theory revisited. Educational Psychologist, 52(1), 50-62. https://doi.org/10.1080/00461520.2016.1221765

Claravall, E. B. (2016). Integrating morphological knowledge in literacy instruction: Framework and principles to guide special education teachers. Teaching Exceptional Children, 48(4), 195-203. https://doi.org/10.1177/0040059915623526

Crosson, A. C., \& McKeown, M. G. (2016). Middle school learners' use of Latin roots to infer the meaning of unfamiliar words. Cognition and Instruction, 34(2), 148-171. https://doi.org/10.1080/07370008.2016.1145121 
Edwards, A. (2017). Cultural-historical theory and pedagogy: The influence of Vygotsky on the field. In Life in schools and classrooms. 153-166. Springer https://doi.org/10.1007/978-981-10-3654-5_10

Fracasso, L. E., Bangs, K., \& Binder, K. S. (2016). The contributions of phonological and morphological awareness to literacy skills in the adult basic education population. Journal of Learning Disabilities, 49(2), 140-151. https://doi.org/10.1177/0022219414538513

Georgia Department of Education. (2014). Georgia Department of Education. special education rules implementation. http://www.parentmentors.org/wp-content/uploads/2013/04/Sp-EdImplementation-Manual-Part-1_2-9-12-1.pdf

Georgia Department of Education. (2016). Georgia Department of Education: Evaluations to determine if a child is eligible for special education. https://www.cherokeek12.net/userfiles/wp-uploads/2016/07/GaDOE-P2P-Initialevaluations-for-eligibility-Fact-Sheet.pdf

Gilham, C., \& Tompkins, J. (2016). Inclusion reconceptualized: Pre-service teacher education and disability studies in education. Canadian Journal of Education/Revue Canadienne de L'éducation, 39(4), 1-25.

Golombek, P. (2017). Innovating my thinking and practices as a language teacher educator through my work as a researcher. In Innovative practices in language teacher education (pp. 15-31). Springer International Publishing. https://doi.org/10.1007/978-3-319-51789-6_2

Goodwin, A. P. (2015). Effectiveness of word solving: Integrating morphological problemsolving within comprehension instruction for middle school students. Reading and Writing, 29(1), 91-116. https://doi.org/10.1007/s11145-015-9581-0

Hamdan, A. R., Anuar, M. K., \& Khan, A. (2016). Implementation of co-teaching approach in an inclusive classroom: Overview of the challenges, readiness, and role of special education teacher. Asia Pacific Education Review, 17(2), 289-298. https://doi.org/10.1007/s12564-016-9419-8

Haynes, M. C., Ryan, N., Saleh, M., Winkel, A. F., \& Ades, V. (2017). Contraceptive knowledge assessment: Validity and reliability of a novel contraceptive research tool. Contraception, 95(2), 190-197. https://doi.org/10.1016/j.contraception.2016.09.002

Howell, P. B., Faulkner, S. A., Cook, C. M., Miller, N. C., \& Thompson, N. L. (2016). Specialized preparation for middle level teachers: A national review of teacher preparation programs. Research in Middle School Level Education Online, 39(1), 1-12. https://doi.org/10.1080/19404476.2015.1115322

Hudson, R. F., Davis, C. A., Blum, G., Greenway, R., Hackett, J., Kidwell, J., \& Schulze, M. (2015). A socio-cultural analysis of practitioner perspectives on implementation of evidence-based practice in special education. The Journal of Special Education, 50(1), 27-36. https://doi.org/10.1177/0022466915613592 
Kushwaha, P., \& Rao, M. K. (2016). Integrating the linkages between learning systems and knowledge process: An exploration of learning outcomes. Business Perspectives and Research, 5(1), 11-23. https://doi.org/10.1177/2278533716671616

Louick, R., Leider, C. M., Daley, S. G., Proctor, C. P., \& Gardner, G. L. (2016). Motivation for reading among struggling middle school readers: A mixed methods study. Learning and Individual Differences, 49, 260-269. https://doi.org/10.1016/j.lindif.2016.06.027

Maftoon, P., Shokouhi, M., \& Birjandi, P. (2017). Strategically mediated reflective practice framework in terms of task, meaningful learning, and interaction. International Journal of Applied Linguistics and English Literature, 6(3), 101-115.

https://doi.org/10.7575/aiac.ijalel.v.6n.3p.101

Mattison, R. (2015). Characteristics of reading disability types in middle school students classified ED. Behavioral Disorders, 34(1), 27-41. https://doi.org/10.1177/019874290803400103

McMillan, J. (2016). Assessment essentials for standards-based education (3rd ed.). Corwin.

Moje, E. B. (2017) Theory and research on literacy as a tool for navigating everyday and school discourses. In: Wortham S., Kim D., May S. (Eds.) Discourse and education. encyclopedia of language and education (3rd ed.), pp. 239-252). Springer, Cham. https://doi.org/10.1007/978-3-319-02243-7_25

O’Connor, R. E., Beach, K. D., Sanchez, V., Bocian, K. M., Roberts, S., \& Chan, O. (2017). Building better bridges: Teaching adolescents who are poor readers in eighth grade to comprehend history text. Learning Disability Quarterly, 40(3), 174-186. https://doi.org/10.1177/0731948717698537

Orellana, M. F., Johnson, S. J., Rodriguez-Minkoff, A. C., Rodriguez, L., \& Franco, J. (2017). An apprentice teacher's journey in "seeing learning." Teacher Education Quarterly, 44(2), 7 .

Özbek, A. B., \& Girli, A. (2017). The effectiveness of a tablet computer-aided intervention program for improving reading fluency. Universal Journal of Educational Research, 5(5), 757- 764. https://doi.org/10.13189/ujer.2017.050508

Peake, C., Diaz, A., \& Artiles, C. (2016). Alphabet writing and allograph selection as predictors of spelling in sentences written by Spanish-speaking children who are poor or good keyboarders. Journal of Learning Disabilities, 50(5), 543-551.

https://doi.org/10.1177/0022219416642188

Polanin, J. R., Maynard, B. R., \& Dell, N. A. (2016). Overviews in education research: A systematic review and analysis. Review of Educational Research, 87(1), 172-203. https://doi.org/10.3102/0034654316631117 
Sauer, J. S., \& Jorgensen, C. M. (2016). Still caught in the continuum: A critical analysis of least restrictive environment and its effect on placement of students with intellectual disability. Inclusion, 4(2), 56-74. https://doi.org/10.1352/2326-6988-4.2.56

Schimmel, N., \& Ness, M. (2017). The effects of oral and silent reading on reading comprehension. Reading Psychology, 38(4), 390-416. https://doi.org/10.1080/02702711.2016.1278416

Snow, C. E., \& Matthews, T. J. (2016). Reading and language in the early grades. The Future of Children, 26(2), 57-74. https://doi.org/10.1353/foc.2016.0012

Spoede, J. T., Jr., Fontenot, C., \& Simpson, C. (2016). The role of the special educator in the inclusive classroom. In General and special education inclusion in an age of change: Roles of professionals involved (pp. 39-54). Emerald Group Publishing Limited. https://doi.org/10.1108/s0270-401320160000032004

Swanson, E., Wanzek, J., Vaughn, S., Fall, A. M., Roberts, G., Hall, C., \& Miller, V. L. (2016). Middle school reading comprehension and content learning intervention for belowaverage readers. Reading \& Writing Quarterly, 33(1), 37-53. https://doi.org/10.1080/10573569.2015.1072068

Truesdell, K. S., \& del Prado Hill, P. (2015). Family literacy and global literature. The Reading Teacher, 68(6), 430-434. https://doi.org/10.1002/trtr.1337

Vinovskis, M. (2015). From a nation at risk to no child left behind: National education goals and the creation of federal education policy. Teachers College Press. https://doi.org/10.1108/09578231011015458

Young, M. C., \& Courtad, C. A. (2016). Inclusion and students with learning disabilities. In General and special education inclusion in an age of change: Impact on students with disabilities (pp. 13-29). Emerald Group Publishing Limited. https://doi.org/10.1108/s0270-401320160000031002 